\title{
HUBUNGAN ANTARA DUKUNGAN KELUARGA INTI DENGAN PROKRASTINASI AKADEMIK MAHASISWA
}

\author{
Saibun Panjaitan ${ }^{1)}$, Marisi Simanungkalit ${ }^{2)}$, Yohanes Wardoyo ${ }^{3)}$, Franky Tuerah ${ }^{4)}$, Nathan Roson ${ }^{5)}$ \\ Yayasan Pondok Kasih Kelompok Belajar Mandiri (KBM) Abdi Gusti Teological Seminary, Nganjuk, Indonesia \\ Email: jefry saibun panjaitan @gmail.com \\ Yayasan Pondok Kasih Kelompok Belajar Mandiri (KBM) Abdi Gusti Teological Seminary, Nganjuk, Indonesia \\ Email: marbungaraja13@gmail.com \\ Abdi Gusti Teological Seminary, Nganjuk, Indonesia \\ Email: Yohanes Waroydo2@gmail.com \\ Abdi Gusti Teological Seminary, Nganjuk, Indonesia \\ Email: Nathan Roson@yahoo.co.id \\ Abdi Gusti Teological Seminary, Nganjuk, Indonesia \\ Email: Franky Tuerah: franky_tuerah@yahoo.co.uk
}

\begin{abstract}
Core family support is one of the external factors that affect students. Each form of family support has aspects including informative, emotional attention, instrumental assistance and assessment assistance. Students are expected to maintain communication with the nuclear family, in order to continue to get support from the nuclear family. The role of the nuclear family as controls, mentors, regulators and supervisors cannot be immediately erased or eliminated just to be independent or free of expression. In procrastination, it is a student's behavior that is not uncommonly realized but is still being lived out, procrastination makes us think irrationally in a conscious state and looks natural by the surrounding environment. Social support, especially core family support is needed to help the student concerned avoid procrastination. This research was conducted with quantitative research with the technique ofcorrelation analysis product moment. From the results of the analysis shows the direction of the relationship between core family support and academic procrastination, while the value of $p<0.01$ in Sig. (2-tailed) shows that there is a relationship between core family support and student academic procrastination.
\end{abstract}

Keywords: procrastination, instrumental, assessment, students

\section{PENDAHULUAN}

Mahasiswa terdiri dari dua kata yaitu maha yang berarti besar dan siswa yang berarti orang yang sedang melakukan pembelajaran, jadi mahasiswa merupakan seseorang yang menjalani jenjang pendidikan yang lebih tinggi dari siswa. Menurut Sarwono (1978) mahasiswa adalah setiap orang yang secara resmi terdaftar untuk mengikuti pelajaran di perguruan tinggi dengan batas usia sekitar 18-30 tahun. Mahasiswa merupakan insan-insan calon sarjana yang dalam keterlibatannya dengan perguruan tinggi (yang makin menyatu dengan masyarakat), dididik dan diharapkan menjadi caloncalon intelektual (Knopfemacher dalam Suwono, 1978). Mahasiswa memegang peranan penting bagi diri sendiri maupun masyarakat, tercapainya pembentukan karakter yang intelektual, berkualitas, berbudi luhur dan bermoral akan menunjang terpacainya peran mahasiswa sebagai iron stock, agent of change, socialcontrol dan moral force.
Perubahan dari siswa menjadi mahasiswa sering kali dianggap sebagai hal yang biasa bahkan hanya seperti kenaikan kelas atau kelulusan, tidak sedikit anggapan yang menyebut perubahan dari siswa menjadi mahasiswa hanya untuk dianggap dewasa dan diberi kebebasankebebasan yang tidak dimiliki atau didapat ketika masih menjadi seorang siswa.Padahal banyak tuntutan dan kewajiban yang menanti baik itu akademik maupun kemasyarakatan, bahkan harus memulai dari nol karena kehilangan atau berkurangnya dukungan-dukungan yang didapat ketika masih menjadi siswa.

Salah satu dukungan yang hilang atau berkurang adalah dukungan keluarga inti, keluarga adalah sumber dukungan sosial yang penting (Rodin dan Solovey dalam Smet, 1994) untuk mengatasi masalah (Santrock, 2002).Mahasiswa dituntut mampu mencari bantuan atau memecahkan masalah sendiri, karena telah berganti lingkungan dimana 
teman, keluarga dan lingkungan yang biasa membantunya kini sulit dijangkau. Belum cukup dengan hilang atau berkurangnya dukungan keluarga inti, mahasiswa pun dituntut untuk segera beradaptasi dengan lingkungannya yang baru. Sebagai seorang akademisi, mahasiswa tidak akan pernah terlepas dari aktivitas belajar dan keharusan mengerjakan tugas-tugas studi. Mahasiswa dituntut untuk memiliki ciri intelektualitas lebih komplek serta situasi proses belajar yang penuh tantangan, hal ini akan membawa kesukaran tersendiri pada diri mahasiswa jika mereka tidak siap dan tidak mampu menghadapi tuntutan tersebut (Mayangsari, 2013).

Mahasiswa diharapkan memiliki kemampuan mengatur waktu efektif dan efisien agar tugas-tugas akademik yang dibebankan kepadanya bisa terselesaikan tepat waktu, namun pada kenyataannya hanya sedikit mahasiswa siap dan mampu mengatur waktu untuk menyelesaikan tugas perkuliahan seperti dikemukakan oleh Djamarah (2002) bahwa banyak mahasiswa yang mengeluh karena tidak dapat membagi waktunya dengan tepat, kapan harus memulai dan mengerjakan sesuatu sehingga waktu yang seharusnya dapat bermanfaat \terbuang dengan percuma. Kurangnya kedewasaan dalam berpikir sering kali memperparah kondisi ini, sehingga mahasiswa memilih hal-hal yang mudah dikerjakan sekalipun itu tidak penting seperti mencari hiburan.

Dalam ranah keilmuan psikologi hal ini sudah tidak asing, bahkan sudah dipelajari sejak lama. Hal ini dikenal sebagai prokastinasi, secara umum diartikan sebagai penundaan atau menundanunda.Prokrastinasi dijuluki the thief of time, prokrastinasi sendiri sudah seperti fenomena gunung es dan mendapatkan perhatian karena termasuk selfdestruction. Penundaan untuk memulai maupun menyelesaikan tugas yang dihadapi, keterlambatan dalam mengerjakan tugas, kesenjangan waktu antara rencana dan kinerja aktual, melakukan aktivitas lain yang lebih menyenangkan daripada melakukan tugas yang harus dikerjakan merupakan aspek-aspek prokrastinasi (Scouwenburg dalam Ferrari dkk, 1995; Ferrari dalam Ahmaini, 2009).

Dukungan keluarga inti merupakan salah satu faktor eksternal yang mempengaruhi mahasiswa, menurut House (Setiadi, 2008) setiap bentuk dukungan keluarga mempunyai aspek-aspek antara lain informatif, perhatian emosional, bantuan instrumental dan bantuan penilaian.

Mahasiswa diharapkan tetap menjalin komunikasi dengan keluarga inti, agar tetap mendapatkan dukungan keluarga inti. Kemandirian bukan berarti lepas seutuhnya atau meninggalkan keluarga inti, kedewasaan dalam berpikir butuh keterbukaan terhadap lingkungan sekitar.Peran keluarga inti sebagai kontrol, pembimbing, pengatur dan pengawas tidak bisa serta merta dihapus atau dihilangkan hanya untuk berdikari atau bebas berekspresi.

Prokrastinasi merupakan perilaku yang tidak jarang disadari namun tetap dijalani, prokrastinasi membuat kita berpikir irrasional dalam keadaan sadar dan kelihatan wajar oleh lingkungan sekitar. Dukungan sosial, khususnya dukungan keluarga inti dibutuhkan untuk membantu mahasiswa bersangkutan terhindar dari prokrastinasi.

\section{LANDASAN TEORI}

Dukungan keluarga inti adalah sikap, tindakan dan penerimaan keluarga terhadap anggotanya sebagai bagian yang tidak terpisahkan dalam lingkungan keluarga yang selalu siap memberikan pertolongan dan bantuan jika diperlukan dalam bentuk materiil maupun non materiil, informasi verbal maupun non verbal, saran, nasehat, bantuan yang nyata atau tingkah laku yang diberikan oleh lingkungan keluarganya atau berupa kehadiran dan hal-hal yang dapat memberikan dukungan emosional dan berpengaruh pada tingkah laku penerimanya dimana orang yang merasa memperoleh dukungan secara emosional merasa lega karena diperhatikan, dipedulikan, dihargai, mendapat kesan yang menyenangkan atau bermanfaat pada dirinya.

Aspek-aspek dukungan keluarga menurut House (Setiadi, 2008) antara lain:

a. Informatif, yakni bantuan informasi yang disediakan agar dapat digunakan oleh seseorang dalam menanggulangi persoalanpersoalan yang dihadapi, ide-ide atau informasi lainnya yang dibutuhkan dan informasi ini dapat disampaikan kepada orang lain yang mungkin menghadapi persoalan yang sama.

b. Perhatian emosional, setiap orang pasti membutuhkan bantuan afeksi dari orang lain. Dukungan ini berupa dukungan simpatik dan empati, cinta, kepercayaan dan penghargaan. Dengan demikian, seseorang yang menghadapi persoalan merasa dirinyal tidak menanggung beban sendiri tetapi masih ada orang lain yang memperhatikan, mau mendengar segala keluhnya, bersimpati dan empati terhadap persoalan yang dihadapinya, bahkan mau membantu memecahkan masalah. 
c. Bantuan instrumental, bantuan bentuk ini bertujuan untuk mempermudah seseorang melakukan aktivitasnya berkaitan dengan persoalan-persoalan yang dihadapinya atau menolong secara langsung kesulitan yang dihadapi misalnya dengan menyediakan peralatan lengkap dan memadai.

d. Bantuan penilaian, yaitu suatu bentuk penghargaan yang diberikan seseorang kepada pihak lain berdasarkan kondisi sebenarnya penderita. Penilaian ini bisa positif dan negatif yang mana pengaruhnya sangat berarti bagi seseorang. Berkaitan dengan dukungan sosial keluarga maka penilaian yang sangat membantu adalah penilaian yang positif. prokrastinasi akademik adalah perilaku spontanitas atau kepribadian dalam menyingkapi tugas dengan melakukan penundaan secara sadar dengan alasan irrasional atau alasan tertentu saat memulai atau menyelesaikan tugas yang terencana dan seharusnya dikerjakan dengan melakukan aktivitas lain sampai timbul niat atau terpaksa karena harus menyelesaikannya akibat beban psikologis dan tanggung jawab atas tugas tersebut.

Aspek prokrastinasi akademik menurut Scouwenburg (dalam Ferrari $\backslash$ dkk, 1995), Ferrari (dalam Ahmaini, 2009) meliputi penundaan dalam memulai menyelesaikan kinerja dalam menghadapi tugas, keterlambatan ataukelambanan dalam mengerjakan tugas,kesenjangan waktu antara rencana dan kinerja aktual dalam mengerjakan tugas, melakukan aktivitas lain yang dipandang lebih menyenangkan dan mendatangkan hiburan daripada menyelesaikan tugas.

\section{METODE PENELITIAN}

Metode penelitian yang digunakan dalam penelitian ini adalah metode penelitian kuantitatif, metode penelitian kuantitatif adalah suatu proses menemukan pengetahuan dengan melakukan pendekatan penelitian terhadap kajian empiris maupun teoritis yang menekankan pada data-data numerikal yang diolah secara stastistik mulai dari pengumpulan data, penafsiran terhadap data tersebut serta penampilan dari hasil.

Populasi yang digunakan sebagai penelitian adalah mahasiswa psikologi UMS, Sampel dalam penelitian ini adalah mahasiswa Fakultas Psikologi UMS minimal semester 4 berdasarkan pada hasil penelitian yang dilakukan oleh Hill dkk (dalam Ferrari, Johnson, dan McCown, 1995) yang menyebutkan bahwa ada peningkatan sekitar 50\% perilaku penundaan pada perubahan dari mahasiswa baru ke mahasiswa tingkat empat selama lebih dari tiga tahun masa perkuliahan.

Penelitian ini menggunakan teknik nonprobability purposivesampling, non-probability sampling adalah teknik pengambilan sampel yang tidak memberi peluang atau kesempatan sama bagi setiap unsur anggota populasi untuk dipilih menjadi sampel. Teknik non-probabilitysampling meliputi sampling sistematis, kuota, eksidental, purposive, jenuh dan snowball. Teknik nonprobabilitypurposive sampling adalah teknik penentuan sampel dengan pertimbangan tertentu (Sugiyono, 2012).

Subjek penelitian sebanyak 249 mahasiswa, terdiri dari 134 mahasiswa semester 5, 101 mahasiswa semester 7, 11 mahasiswa semester 9 dan 3 mahasiswa semester 11. Pengumpulan data menggunakan skala dukungan keluarga inti dan skala prokrastinasi akademik yang selanjutnya dianalisis menggunakan teknik korelasi product moment dari Karl Pearson (Azwar, 2012) dengan program SPSS 15.0 WindowsEvaluation Version.

\section{HASIL PENELITIAN DAN PEMBAHASAN}

Berdasarkan hasil penelitian menggunakan teknik analisis productmoment dari Pearson dengan program SPSS 15.0 Windows EvaluationVersion diperoleh nilai koefisien korelasi (r) sebesar 0,442 dan Sig. (2- tailed) $=0,000$. Tanda negatif (-) pada $r$ menunjukkan arah hubungan antara dukungan keluarga inti dengan prokrastinasi akademik, sedangkan nilai $\mathrm{p}<0,01$ pada Sig. (2-tailed) menunjukkan ada tidaknya hubungan antara dukungan keluarga inti dengan prokrastinasi akademik. Jadi hasil penelitian menunjukkan ada hubungan negatif yang signifikan antara dukungan keluarga inti dengan prokrastinasi akademik, maka variabel dukungan keluarga inti dapat digunakan sebagai prediktor untuk memprediksi prokrastinasi akademik. Artinya dukungan keluarga inti mempengaruhi tingkat prokrastinasi akademik mahasiswa, di mana semakin tinggi dukungan keluarga inti maka semakin rendah prokrastinasi akademik dan sebaliknya semakin rendah dukungan keluarga inti maka semakin tinggi prokrastinasi akademik.

Hasil penelitian menunjukkan dukungan keluarga inti pada mahasiswa psikologi UMS 
tergolong tinggi, hal ini dilihat dari rerata empirik $(\mathrm{RE})=65,27$ dan rerata hipotetik $(\mathrm{RH})=50$. Sedangkan prokrastinasi akademik pada mahasiswa psikologi UMS tergolong rendah, hal ini dilihat dari rerata empirik $(\mathrm{RE})=95,84$ dan rerata hipotetik $(\mathrm{RH})=112,5$. Artinya mahasiswa psikologi UMS melihat dukungan keluarga inti sebagai suatu hal yang bisa mengurangi prokrastinasi akademik, adanya dukungan keluarga inti yang baik menjadi faktor rendahnya prokrastinasi akademik di fakultas psikologi UMS. Dilihat dari kategorisasi skala dukungan keluarga inti maka ada 9mahasiswa $(3,9 \%)$ memiliki tingkat dukungan keluarga inti yang tergolong sedang, 135 mahasiswa (58\%)memiliki tingkat dukungan keluarga inti yang tergolong tinggi dan 88 mahasiswa $(38,1 \%)$ memiliki tingkat dukungan keluarga inti yang tergolong sangat tinggi. Artinya sebagian besar mahasiswa psikologi UMS mendapatkan dukungan keluarga inti yang baik, meskipun tidak tinggal lagi bersama keluarga inti. Adanya dukungan keluarga inti membuat mahasiswa psikologi UMS mendapatkan pertolongan praktis dan konkrit, sehingga termudahkan apabila membutuhkan pertolongan dalam menyelesaikan masalah yang dihadapi.

Meskipun keluarga inti tidak selalu bersama mahasiswa psikologi UMS, namun keberadaan dapat menjadi sumber informasi bagi mahasiswa psikologi UMS khususnya pengalaman yang mereka miliki. Sehingga mahasiswa psikologi UMS dapat lebih mengetahui baik buruknya langkah yang mereka tempuh, serta mampu mengendalikan emosinya.Hal ini sesuai dengan aspek dukungan keluarga menurut Setiadi (2008), yang meliputi dukungan informasional, dukungan instrumental, dukungan penilaian dan dukungan emosional.

Dilihat dari kategorisasi skala prokrastinasi akademik maka ada 10 mahasiswa $(4,24 \%)$ memiliki tingkat prokrastinasi akademik yang tergolong sangat rendah, 121 mahasiswa $(52,38 \%)$ memiliki tingkat prokrastinasi akademik yang tergolong rendah, 98 mahasiswa $(42,42 \%)$ memiliki tingkat prokrastinasi akademik yang tergolong sangat sedang dan 2 mahasiswa $(0,87 \%)$ memiliki tingkat prokrastinasi akademik yang tergolong tinggi. Artinya sebagian besar mahasiswa psikologi UMS memiliki tingkat prokrastinasi akademik yang rendah, di mana jumlah mahasiswa psikologi UMS yang melakukan sangatlah sedikit. Mahasiswa psikologi UMS memiliki kinerja yang bagus sehingga cepat dan tepat waktu dalam menyelesaikan tugas yang dihadapi, selaras dengan rencana dan kinerja aktual dalam mengerjakan tugas.
Mahasiswa psikologi UMS fokus dalam menyelesaikan masalah yang dihadapi, mengesampingkan aktivitas lain yang lebih menarik dan menyenangkan. Sumbangan efektif dukungan keluarga inti terhadap prokrastinasi akademik sebesar 19,5\% menunjukkan seberapa besar dukungan inti mempengaruhi prokrastinasi akademik, artinya masih ada $80,5 \%$ faktor lain yang mempengaruhi prokrastinasi akademik. Apabila dibuat 5 kategorisasi, terdiri dari sangat tinggi, tinggi, sedang, rendah dan sangat rendah. Maka sumbangan efektif dukungan keluarga inti terhadap prokrastinasi akademik tergolong sangat rendah, karena kurang dari 20\%.Hal ini senada dengan pendapat Milgram (1998) yang menyebutkan faktorfaktor yang mempengaruhi prokrastinasi akademik dikategorikan menjadi dua macam, yaitu faktor internal dan faktor eksternal. Faktor internal terdiri atas kondisi fisik dan psikis, sedangkan faktor eksternal terdiri atas gaya pengasuhan orang tua, kondisi lingkungan dan tingkat sekolah.

Sangat rendahnya dukungan keluarga inti terlihat implisitnya dukungan keluarga inti pada faktor eksternal prokrastinasi akademik, tidak disebutkan secara eksplisit.Namun penelitian ini membuktikan bahwa dukungan keluarga inti berpengaruh terhadap prokrastinasi akademik, sekalipun pengaruhnya sangat rendah.Meskipun begitu adanya dukungan keluarga inti dapat menjadi salah satu solusi mengurangi tingkat prokrastinasi akademik mahasiswa, sehingga mahasiswa dapat mencapai prestasi yang optimal.

\section{KESIMPULAN}

Berdasarkan penelitian dan pembahasan, maka kesimpulan yang dapat diambil dari penelitian ini adalah:

1. Ada hubungan negatif yang signifikan antara dukungan keluarga inti dengan prokrastinasi akademik, hal ini ditunjukkan hasil koefisien korelasi sebesar -0,442; $\mathrm{p}=0,000(\mathrm{p}<0,01)$. Semakin tinggi dukungan keluarga inti maka semakin rendah prokrastinasi akademik, sebaliknya semakin rendah dukungan keluarga intimaka semakin tinggi prokrastinasi akademik.

2. Dukungan keluarga inti pada subjek tergolong tinggi, hal ini ditunjukkan rerata empirik $(\mathrm{RE})=65,27$ dan rerata hipotetik $(\mathrm{RH})=50$.

3. Prokrastinasi akademik pada subjek penelitian tergolong sedang, hal ini 
ditunjukkan rerata empiric $(\mathrm{RE})=95,84$ dan rerata hipotetik $(\mathrm{RH})=112,5$.

\section{SARAN}

Berdasarkan hasil penelitian yang diperoleh pembahasan dan kesimpulan, maka penulis mengajukan beberapa saran sebagai berikut:

1. Bagi mahasiswa psikologi UMS Diharapkan kepada mahasiswa untuk menjaga hubungan dengan keluarga inti, baik itu dalam hal komunikasi maupun kedekatan emosi. Jarak bukanlah halangan, jangan hiraukan hinaan. Kemandirian dan kedewasaan bukan berarti lepas dari keluarga inti, melainkan berdiri sejajar bersama mereka. Saling terbuka, menerima-memberi masukan dan menerimamemberi bantuan.

2. Bagi keluarga inti Diharapkan kepada keluarga inti untuk tetap perduli antar anggota keluarga, memprioritaskan keluarga dari kesibukannya masing-masing. Saling mengawasi dan menasehati agar anggota keluarga tidak salah dalam mengambil tindakan dan keputusan. Berusaha untuk selalu siap memberi bantuan dan semangat, serta bersedia menjadi sandaran untuk meluapkan keluh kesah curahan hati anggota keluarga.

3. Bagi fakultas psikologi UMS Diharapkan kepada fakultas lebih peduli terhadap mahasiswanya, mampu menjebatani atau menggantikan peran maupun fungsi orang tua. Sebagai jurusan yang membidangi psikologi, sudah selayaknya permasalahanpermasalahan psikologis yang ada di fakultas perlu diminimalisir. Sehingga menjadi pembeda dengan jurusanjurusan akademik lainnya, sekaligus menjadi lahan pengaplikasian psikologi.

4. Bagi praktisi psikologi dan penelitian lain Diharapkan kepada praktisi psikologi agar lebih membumikan keilmuwan psikologi disamping peka dalam merespon isu-isu terkini, tidak berkutat pada isu-isu yang sama. Tidak hanya merespon isu melainkan juga mengangkat isu, sehingga menambah kekayaan wacana ilmu psikologi. Agar seseorang yang melakukan prokrastinasi tidak hanya dipandang negatif maupun positif, melainkan seseorang yang membutuhkan bantuan selayaknya orang yang mengalami gangguan psikologis lainnya. Diharapkan kepada peneliti lain untuk mengangkat atau menemukan variabel lain yang mampu mengurangi tingkat prokrastinasi akademik, sehingga masalah prokrastinasi bisa ditekan maupun diselesaikan.

\section{DAFTAR PUSTAKA}

Arikunto, S. (2006).Prosedur Penelitian: Suatu Pendekatan Praktek. Jakarta: PT RinekaCipta

Akinsola, M., Tella, A. and Tella A.(2007).Correlation of Academic Procrastination and Mathematics Achivement of University UndergraduateStudent. Eurasia Journal of Mathematics, Science \& Technology Education, 3, 4, 363-367

Azwar, S. (2012).Metode penelitian.Yogyakarta: Pustaka Pelajar (2013).Penyusunan Skala Psikologi (Edisi Dua).Yogyakarta: Pustaka Pelajar.

Balkis, M. \& Duru, E. (2009).Prevelence of Academic Procrastination Behavioramong Pre-service teacherand its Relationship withdemographics and IndividualPreverence. Journal of Theory Practice in Education, 5, 1, 18-32

Bernard, M. E. (1992). Procrastination Later. Australia: AustraliaPrint Group

Beswick, G. \& Mann, L. (1994). Stateorientation andprocrastination. In J. Kuhl \&J. Beckmann (Eds.), Volition and personality: Action Versus State Orientation (pp. 391396). Gottingen, Germany: Hogrefe \& Huber

Boice, R. (1996). Procrastination: A Novel, Practical Approach.Westport, CT: PraegerPublisher

Bruno, F. J. (1998). Stop Prokracrastinating. Jakarta:PT. Gramedia Pustaka Utama

Burka, J. B. \& Yuen, L. M. (2008).Procrastination: Why you do it. What to do about it. UnitedStates of America: Da CapoPress A Member of thePerseus Books Group

Chaplin, J.P. (2005). Kamus Lengkap Psikologi. Jakarta: PT Raja Grafindo Persada

Chu, A. \& Choi, J. N. (2005).Rethingking Procrastination:Possitive Effects of "Active"Procrastination Behavior onAttitude and Performance. Journal of Social Psychology, 145, 4, 245-26 
Cohen, S. (1992). The Meaning and Measurement of Social Support: Stress, Social Support and Disorder. NewYork: Hemisimere Press

Djamarah, S. B. (2002). Rahasia Sukses Belajar. Jakarta:Rineka Cipta

Erma, Erma. (2013). Hubungan Antara Harga Diri Dengan Prokrastinasi Akademik Pada Mahasiswa.Skripsi.Surakarta: Universitas Muhammadiyah Surakarta

Ferrari, J. R. \& Tice, D. M. (2000).Procrastination as a Self-Handicap for Men andWomen: A Task AvoidanceStrategy in a LaboratorySetting. Journal of Research in Personality 34, 73-83

Ferrari, J.R., Johnson, J. L., McCown,W. (1995). Procrastination and Task Avoidance: Theory, Research and Treatment.New York: Plenum Press

Fibrianti, I. D. (2009). Hubungan Antara Dukungan Sosial Orangtua dengan Prokrastinasi Akademik dalam Menyelesaikan Skripsi pada Mahasiswa Fakultas Psikologi Universitas Diponegoro Semarang.Skripsi. Semarang: FakultasPsikologi UniversitasDiponegoro Semarang

Fiore, N. A. (2006). The Now Habit: A Strategic Program For Overcoming Procrastination An Enjoying Guilt Free Play.New York: Penguin GroupFrancis, S. dan Satiadarma, M. P.(2004). Pengaruh Dukungan Keluarga terhadap Kesembuhan IN yang Mengidap Penyakit Kanker Payudara.Jurnal IlmiahPsikologi "ARKHE", Th. 9no. 1

Friedman, M. M. (1998). KeperawatanKeluarga Teori dan Praktik(Edisi Ketiga). Jakarta: EGC

Gottlieb, B.H. (1983). Social supportstrategies guidelinesformental health practice. Baverly Hills: Sage Publications.

Gunarsa, S.D. \& Gunarsa, Y.S.D. (1995).Psikologi Praktis:anak, remaja dan keluarga. Jakarta: BPK Gunung Mulia.

Gunawinata, V. A. R., Nanik, Nanik dan Lasmono, H. K. (2008). Perfeksionisme, Prokrastinasi Akademik, dan Penyelesaian Skripsi Mahasiswa. Anima:Indonesian PsychologicalJournal. No. $\quad$ 3.Vol. 23.Hal.256-276

Hadi, S. (1998).Statistik 2. Yogyakarta: Andi Offset (2000).Statistik 3. Yogyakarta: Andi Offset (2001).Metodology

ResearchII.

Yogyakarta: Andi Offset

Harris, N. N. \& Sutton, R. I. (1983). Task Procrastination in Organizations: A
Framework for Research. HumanRelations, 36, 11, P. 987-996

Haviland, W.A. (1993). AntropologiJilid 2 (edisi 4). Jakarta: Penerbit Erlangga

Hayyinah, Haniyyah. (2004). Religiusitas dan Prokrastinasi Akademik Mahasiswa.JurnalPsikologika No. 17 Tahun IXJanuari 2004. Yogyakarta: Fakultas Psikologi Universitas Islam Indonesia

Howell, A. J. \& Watson, D. C. (2007). Procrastination: Associations with achievement goal orientation and learning strategies. Personality andIndividual Differences, 43, 1,167-178

Iskender, M. (2011).The Influence of Selfcompation on Academic Prokrastination and Dysfunctional Attitudes.Educational Research andReviews, 6, 2, 230-234

Jerry, N \& Newcombe, K. (2005). Saya akan Melakukannya ...besok!. Jakarta: Metanoia

Kartadinata, I. \& Tjundjing, S. (2008). I love you tomorrow: Prokrastinasi akademik dan manajemen waktu. Anima:Indonesian PsychologicalJournal 2008, Vol. 23, 2, 109119

Khairuddin, H. (1997). SosiologiKeluarga. Yogyakarta: Liberty Yogyakata.

Klassen, R. M., Ang, R. P., Chong, W. H., Krawchuk, L. L., Huan, L. Y. F. \& Yeo, L. S. (2009). A Cross-cultural Study of Adolescent Procrastination.Journal of Research onAdolescence, 19, 4, 799-811

Knaus.(2002). Procrastinationworkbook. Publisher: New Harbinger Publications Inc, USA

LaForge, M. (2008).Applying explanatory style to academic procrastination.Journal ofClemson University, 16, 2,418-529

Larson, C. C. (1992). The effects of a cognitivebehavioral education program on academic procrastination. Dissertation Abstracts International, 53, 2530

Lubis, N. L. (2011). Memahami Dasar-Dasar KonselingDalam Teori dan Praktik. Kota: Bandung

Mifflin Company, H. (2000). TheAmerican HeritageDictionary of the English Language, Fourth Edition.

Boston, USA: Houghton Mifflin Company Milgram, N., Mey-Tal, G. and Levison, Y. (1998). Procrastination Generalized or Specific in College Student and Their Parents. Journal Personality and Individual Differences, 25, 297-316 
Mubarak, W. I., Santoso, B. A., Rozikin, K., Patonah, S. (2006). Ilmu Keperawatan Komunitas 2, Cetakan 1. Jakarta: Sagung Seto

Muhid, A. (2009). Hubungan antara Self-Control dan Self- Efficacy dengan Kecenderungan Perilaku Prokrastinasi Akademik Mahasiswa Fakultas Dakwah IAIN Sunan Ampel Surabaya.Jurnal IlmuDakwah. No. 1.Vol. 18.Hal.577-588

Onwuegbuzie, A. J. (2004). Academic Procrastination and Statistic Anxiety. Assessment \&Evaluation in HigherEducation, 29, 1, 3-19

Ozer, B. U., Ferrari, J. R. (2011). Gender Orientation and Academic Procrastination: Exploring Turkish High School Student. Individual Differences Research, 9, 1,22-40

Rachmahana, R. S. (2002). Prokrastinasi Akademik pada Mahasiswa.Psikodimensia;Kajian Ilmiah Psikologi, 2, 3,132-137

Riduwan.(2010). Belajar MudahPenelitian Untuk Guru-Karyawan Dan PenelitiPemula. Bandung: Alfabeta

Riva'i, M. Z. (2012). HubunganAntara Dukungan Keluarga Inti Dengan Motivasi BelajarPada Pelajar SMP. Skripsi. Surakarta: Universitas Muhammadiyah Surakarta

Rizvi, A., Prawitasari, J. E., \& Soetjipto, H. S. (1997).Pusat Kendali dan Efikasi Diri sebagai Prediktor terhadap Prokrastinasi Akademik Mahasiswa.JurnalPsikologika No.3 tahun II.Yogyakarta

Rumiani, Rumiani. (2006). Prokrastinasi Akademik Ditinjau dari Motivasi Berprestasi dan Stres Mahasiswa.Jurnal PsikologiUniversitas DiponegoroSemarang Vol 3, No. 2, hal37-48

Santrock, J. W. (2002). Life SpanDevelopment: PerkembanganMasa Hidup (edisi 5, jilid ll). Jakarta: Erlangga (2009).PsikologiPendidikan (edisi 3). Jakarta: Salemba Humanika

Sarafino, E. P. (1994). Psychologyhealth: Biopsychosocialinteractions. New York: John Whiley \& Sons, inc

Sarwono, S. W. (2003). Psikologi Remaja. Jakarta: PT Raja Grafindo Persada

Schraw, G., Wadkins, T., Olafson, L.(2007). Doing The Things We Do: A Grounded Theory Of Academic Procrastination. Journal of EducationalPsychology 99

Sepehrian, F., \& Jabari Lotf, J. (2011).The effect of copying styles and gender on academic procrastination among university students.
Journal ofBasic \& Applied ScientificResearch, 12, 1, 2987-2993

Setiadi, Setiadi. (2008). Konsep danProses KeperawatanKeluarga. Jakarta: Graha Ilmu

Setiawati, S., Dermawan, A. C. (2008).Penuntun praktis Asuahankeperawatan

KeluargaCetakan I, Edisi ke 2. Jakarta: Trans Info Media.

Sirois, F. M. (2004) Procrastination And Counterfactual Thinking: Avoiding What Might Have Been. The British Journal OfSocial Psychology, 43,2, 269-286

Smet, B. (1994). Psikologi Kesehatan. Jakarta: PT Gramedia

Soekanto, S. (1990).SosiologiKeluarga Tentang Ihwa lkeluarga, Remaja, dan Anak.Jakarta: Rineka Cipta

Sokolowska, J. (2009). Behavioral,cognitive, affective, and Motivational Dimensions ofAcademic Procrastinationamong Communitty CollegeStudents: $\quad A Q$ MethodologyApproach. Dissertation: AA, LaGuardia Community College, City University of New York

Solomon, L. J. and Rothblum, E. D. (1984). Academic Procrastination: Frequency and Cognitive-Behavioral Correlates. Journal of Counseling Psychology. 31, 4,503-509. AmericanPsychological Association,Inc

Sudiharto.(2007). Asuhan Keperawatan Keluargadengan PendekatanKeperawatan Transkultural. Jakarta: EGC.

Sugiyono, Sugiyono. (2012). Metode Penelitian Kuantitatif Kualitatif Dan $R \& D$ Cetakan 17. Bandung: CV Alfabeta

Suprajitno. (2004). AsuhanKeperawatan Keluarga:Aplikasi Dalam Praktik. Jakarta: EGC

Surijah, E.A. \& Sia, T. (2007). Mahasiswa versus tugas: prokrastinasi akademik dan conscientiousness. Anima Indonesia Psychological Journal, 22, 4, 352-374

Suryabrata, S. (2000). Metodologi Penelitian. Jakarta: PT Raja Grafindo Persada.

Thakkar, N. (2009). Why Procrastination: an Investigation of the root Couses BehindProkrastination. Lethbridge Undergraduate Research Journal, 4, 2

Timpe, A. D. (1999). Seri Manajemen Sumber Daya Manusia,Mengelola Waktu.Terjemahan Susanto Boedidharmo. Jakarta: PT Elex Media Komputindo, Kelompok Gramedia

Tondok, M. S., Ristyadi, H., dan Kartika, A. (2008). Prokrastinasi akademik dan Niat Membeli 
KERUSSO, VOLUME 3 NUMBER 1 MARET 2018

Skripsi.Anima:Indonesian Psychological Journal. No. 1.Vol. 24.Hal.76-87

Utomo, D. (2010). Hubungan Antara Pemalasan Sosial DenganProkrastinasi Akademik.Skripsi. Surakarta: Universitas Muhammadiyah Surakarta

Wyk, L. V. (2004). The Relationship Between Procrastination and Stress in The Life of The High School Teacher. Thesis.Universitas of Pretoria 